\title{
CULTURALLY RELEVANT FOOD AND LIFESTYLE INTERVENTIONS DELIVERED THROUGH SOCIAL MEDIA LED TO SUSTAINABLE PUBLIC HEALTH
}

\author{
Jinal A. Shah* and Somya Gupta \\ Rujuta Diwekar, Mumbai, India
}

\begin{abstract}
:
Background: A public health project was conducted for twelve weeks starting January 2018 with a follow up in December 2018. The objective was to study the impact of culturally relevant food and lifestyle guidelines on public health. i.e a Food systems approach versus a Food group approach. The secondary objective was to introduce the concept of metabolic markers of health in public health narrative and also to point towards detrimental effects of gadget and plastic use. Lastly, to demonstrate that social media can be an effective tool to reach out to a large group of participants.

Methods: Cumulative weekly guidelines were given to participants for twelve weeks. More than 125,000 participants from over 40 countries registered for the project. On an average, 15000 participants consistently filled the weekly follow up forms. The participants self-rated their score on six metabolic health parameters: energy levels during the day, sleep quality in the night, sweet cravings post meals, acidity/bloating/indigestion, exercise compliance, and pain during PMS/period (for women participants) every four weeks. Inch-loss from waist at the navel was also tracked.
\end{abstract}

Results: A significant improvement in metabolic health parameters (40 to 65 percent. on average) was observed along with inches lost from the waist (more than 80 percent of participants lost at least an inch). Cultural relevance also ensured sustainability as most of the consistent participants (more than 90 percent) continue to inculcate the guidelines in their daily lives even after an year.

Conclusion: Public health messages should focus on advocating culturally compliant eating practices along with increase in physical activity and exercise and improvement in daily habits like gadget and plastic use.

Keywords: Public health, Food systems, Environment, Metabolic health, Diet diversity, Social media

\section{Introduction}

Public health continues to be a challenge worldwide, 1 especially in low and middle income countries (LMIC) like India, even while diet trends are proliferating. The food group approach - breaking down food into carbs, proteins, fats, etc., and then deciding what to eat, has only led to more confusion amongst the general population. We therefore feel the definition of health needs to move beyond the carbs-protein-fat-calories narrative; and it needs to be looked at from a much broader perspective, a multi-disciplinary approach that links individual health to local economy and global ecology; and it needs to account for climate, crop cycle, agricultural practices, cooking traditions and food heritage of each region. This is the Food systems approach.2

In our work as Nutritionists, we work with people from all walks of life who are suffering from metabolic disorders. From our experience of providing nutrition guidelines and lifestyle interventions to such individuals, we found out that culturally relevant advice on food, and lifestyle in general, is most effective and is sustainable in the long term. It is easier to adopt in daily life, appeals to common sense and has a positive impact on health. 
This led us to conduct this fitness project for public health with the objective of studying the large scale impact of these kind of interventions.

Our interventions broadly focused on the following three categories for a well-rounded public health intervention -
a) Food and eating practices-related, ${ }^{3-7}$
b) Physical activity and exercise-related ${ }^{8,9}$ and
c) Lifestyle and habits-related. ${ }^{10,11}$

Twelve interventions were selected and it was decided that every week one intervention (guideline) will be introduced to the participants. They will then follow those guidelines cumulatively, so that it's easy to adopt in their daily life without making any significant adjustments.

Our secondary objective was to broaden the criteria used to determine health.12-15 Currently, weight loss is the primary criteria that is used by general population. However, metabolic health is often neglected, even though it's an important measure of well-being. We selected 6 metabolic health parameters for this project as surrogate measures of good health instead of weight loss.

These were -

1. Energy levels during the day,

2. Sleep quality in the night,

3. Sweet cravings post meals,

4. Acidity/bloating/indigestion,

5. Exercise compliance, and

6. Pain during PMS/period (for women participants only).

In addition to these parameters, we also used inch loss from the navel as an objective measurement of improvement in overall health. 13

Another secondary objective of the project was to demonstrate that social media can be used as an effective and a positive medium for disseminating large scale public health advice. The entire project was conducted on our social media handles. Textual posts, videos and visual graphics were used to ensure that the messages reach the participants in the form they find the easiest to understand.

\section{Methods}

A questionnaire was created using google forms and was published on our social media channels in the first week of Jan 2018. We kept it open for 24 hours and during that time more than 125000 participants registered from over 40 countries. These participants self-rated their score on the 6 metabolic health parameters on a scale of 1-5. There was no exclusion criteria (except the existing age restrictions on social media channels). 
Every week, for the next 12 weeks, the participants filled a google form which asked them to rate their adherence to the guidelines. Once every 4 weeks, the google form also asked them to rate themselves on the 6 metabolic health parameters and also to record inch loss measured at the navel since the start of the project. They also answered some subjective questions related to plastic usage, gadget usage, food perception, diet diversity, etc.

The weekly forms were made optional for the participants. On an average, 15000 participants filled out the weekly forms. Out of these, we selected 1500 participants who filled out every single weekly form. We called them consistent participants.

At the end of 12 weeks, we collated all the data from the weekly google forms. The data was cleaned for missing entries and duplicates. Statistical averages were taken for all 6 metabolic health parameters at 4 points beginning of the project, end of week 4 , end of week 8 and end of week 12 . We then calculated the percentage improvement in each parameter over the period of 12 weeks. In addition, we also calculated the percentage of participants who lost 1 inch, 2 inches, or more than 2 inches from the navel over the entire 12 weeks. This process was repeated again with only data from consistent participants.

To test for sustainability of the guidelines, we asked the participants to fill a questionnaire through a google form at the end of the year, in December 2018.

\section{Results}

1. Percentage improvement in Metabolic Health parameters (based on self-rating by participants on a scale of 15) -

\begin{tabular}{|l|l|l|}
\hline Metabolic health parameters & $\begin{array}{l}\text { Improvement in } \\
\text { all participants }\end{array}$ & $\begin{array}{l}\text { Improvement in } \\
\text { consistent participants }\end{array}$ \\
\hline Energy levels through the day & $33 \%$ & $44 \%$ \\
\hline Sleep quality during the night & $31 \%$ & $41 \%$ \\
\hline Acidity/ bloating/ indigestion & $52 \%$ & $68 \%$ \\
\hline Sweet cravings post meals & $51 \%$ & $66 \%$ \\
\hline Exercise compliance through the week & $44 \%$ & $54 \%$ \\
\hline Pain during PMS/ Period (for women only) & $48 \%$ & $53 \%$ \\
\hline
\end{tabular}

3. Inch loss at the navel -

\begin{tabular}{|l|l|l|}
\hline Inch loss at navel & All participants & Consistent participants \\
\hline Up to 1 inch & $38 \cdot 4 \%$ & $41 \cdot 7 \%$ \\
\hline $1-2$ inches & $22 \cdot 8 \%$ & $27 \cdot 8 \%$ \\
\hline$>2$ inches & $12 \cdot 4 \%$ & $13 \cdot 0 \%$ \\
\hline
\end{tabular}


4. Percentage of participants reporting on other health parameters (reported through questionnaire) -

\begin{tabular}{|l|l|l|}
\hline Health parameters & $\begin{array}{l}\% \text { of All } \\
\text { participants }\end{array}$ & $\begin{array}{l}\% \text { of Consistent } \\
\text { participants }\end{array}$ \\
\hline Started strength training & $56 \%$ & $62 \%$ \\
\hline Reduced contact of plastic with food & $69 \%$ & $69 \%$ \\
\hline Fitness perception changed & $74 \%$ & $79 \%$ \\
\hline
\end{tabular}

5. Highlights from the questionnaire posed at the end of the year - (for sustainability of guidelines)

\begin{tabular}{|l|l|}
\hline Questions- & $\begin{array}{l}\% \text { of participants reporting } \\
\text { 'YES' }\end{array}$ \\
\hline Consistently followed guidelines? & $91 \%$ \\
\hline Metabolic health continue to improve? & $75 \%$ \\
\hline Developed a positive mind-set towards health? & $74 \%$ \\
\hline Lost further inches from navel? & $70 \%$ \\
\hline No more food fads? & $65 \%$ \\
\hline
\end{tabular}

\section{Discussion}

As reported by participants, there was significant improvement in metabolic health parameters across the spectrum. It was also a consistent improvement throughout the 12 weeks as described in results above. In addition, the participants also reported steady inch loss at navel, another marker of improved health. Lastly, the guidelines were being consistently followed even at the end of one year, pointing to sustainability of the approach.

Public health messages therefore should focus on advocating local, culturally compliant and traditional foods and eating practices along with increase in physical activity and exercise and improvement in daily habits like gadget and plastic use.

There is scope of further research in similar studies where existing conditions and daily routine followed by participants are accounted for, exclusions are noted for participants on medication, etc., and individual contribution of interventions towards improvement of health are empirically calculated. Further research is also needed to measure the impact on non-communicable diseases the participants might already be suffering from.

Through this project, we were able to reach out to a large number of participants spread across the globe by using social media channels. We used video content, visual content and textual content to give out the guidelines. Social media therefore has a role to play as an effective channel to spread public health messages and further studies are required to find out which type of content has the highest penetration and effectiveness.

\section{References}

Arredondo A, Azar A, Recamán AL. Diabetes, a global public health challenge with a high epidemiological and economic burden on health systems in Latin America. Global Public Health 2018; 13: 780-7. 
Food Planet Health, Healthy Diets From Sustainable Food Systems. -Available at: https://eatforum.org/content/uploads/2019/01/EAT-Lancet_Commission_Summary_Report.pdf

Pem D, Jeewon R. Fruit and vegetable intake: Benefits and progress of nutrition education interventionsnarrative review article. Iran J Public Health 2015; 44: 1309-21.

Njike VY, Smith TM, Shuval O, Shuval K, Edshteyn I, Kalantari V, Yaroch AL. Snack food, satiety, and weight. Advances in Nutrition 2016; 7: 866-78.

Sharma H, Zhang X, Dwivedi C. The effect of ghee (clarified butter) on serum lipid levels and microsomal lipid peroxidation. Ayu 2010; 31: 134-40.

Nicklas TA, O'Neil CE, Fulgoni VL. Rice consumption is associated with better nutrient intake and diet quality in adults: National Health and Nutrition Examination Survey (NHANES) 2005-2010. Food and Nutrition Sciences 2014; 5: 525-32.

NicklasTA, O'Neil CE, Fulgoni VL 3rd. Snacking patterns, diet quality, and cardiovascular risk factors in adults. BMC Public Health 2014; 14: 388.

Büssing A, Michalsen A, Khalsa SBS, Telles S, Sherman KJ. Effects of yoga on mental and physical health: A short summary of reviews. Evidence-Based Complementary and Alternative Medicine 2012; 2012: 165410.

Westcott WL. Resistance training is medicine: effects of strength training on health. Current Sports Medicine Reports 2012; 11: 209-16.

Jung SI, Lee NK, Kang KW, Kim K, Lee DY. The effect of smartphone usage time on posture and respiratory function. Journal of Physical Therapy Science 2016; 28: 186-9.

Thompson RC, Moore CJ, vom Saal FS, Swan SH. Plastics, the environment and human health: current consensus and future trends. Philosophical Transactions of the Royal Society B: Biological Sciences 2009; 364: 2153-66.

Lee HY, Yang HK, Song HJ, Chang HJ, Kang JY, Lee SH, Han S, Kim YK. Metabolic health is more closely associated with decrease in lung function than obesity. PLoS ONE 2019; 14: e0209575.

Park J, Lee ES, Lee DY, Kim J, Park SE, Park C-Y, Lee W-Y, Oh K-W, Park S-W, Rhee E-J. Waist circumference as a marker of obesity is more predictive of coronary artery calcification than body mass index in apparently healthy Korean adults: The Kangbuk Samsung Health Study. Endocrinology and Metabolism 2016; 31:559-66.

Stefan N, Kantartzis K, Machann J, Schick F, Thamer C, Rittig K, Balletshofer B, Machicao F, Fritsche A, Häring H-U. Identification and characterization of metabolically benign obesity in humans. Archives of Internal Medicine 2008; 168:1609-16.

Stefan N, Häring HU, Hu FB, Schulze MB. Metabolically healthy obesity: epidemiology, mechanisms, and clinical implications. Lancet Diabetes \& Endocrinology 2013;1:152-62. 


\section{Appendix}

Figure 1. Individual metabolic health parameters improvement over 12 weeks (self-reported by consistent participants on a scale of 1-5) - The numbers in the charts are averages of the ratings.
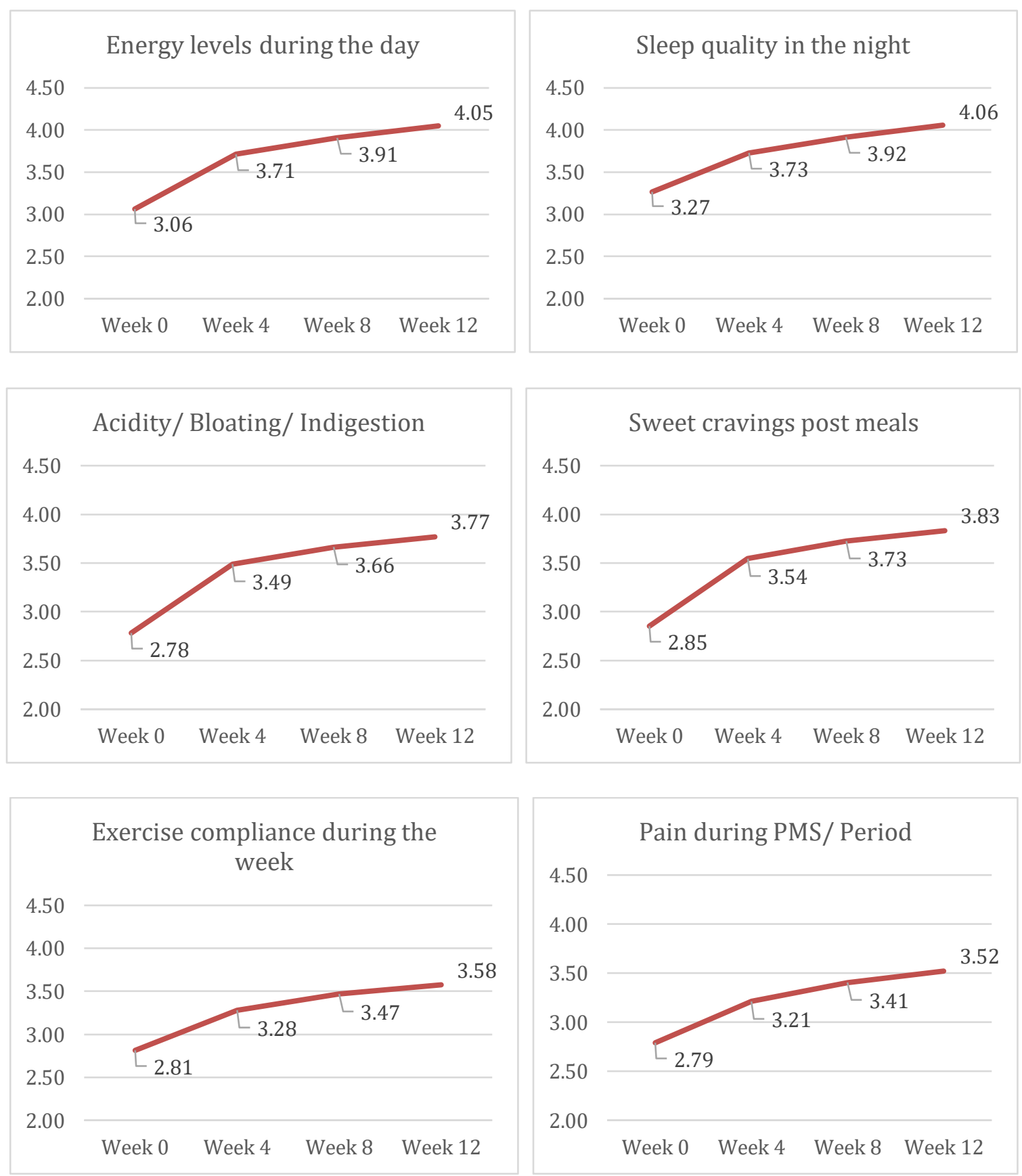